\title{
Supramolecular Approach for Fine-Tuning of the Bright Luminescence from Zero- Dimensional Antimony(III) Halides
}

\author{
Viktoriia Morad, Sergii Yakunin, and Maksym V. Kovalenko*
}

Cite This: ACS Materials Lett. 2020, 2, 845-852

Read Online

ABSTRACT: Halides of $\mathbf{n s}^{2}$ metal ions have recently regained broad research interest as bright narrowband and broadband emitters. $\mathrm{Sb}(\mathrm{III})$ is particularly appealing for its oxidative stability (compared to $\mathrm{Ge}^{2+}$ and $\mathrm{Sn}^{2+}$ ) and low toxicity (compared to $\mathrm{Pb}^{2+}$ ). Square pyramidal $\mathrm{SbX}_{5}$ anion had thus far been the most common structural motif for realizing high luminescence efficiency, typically when cocrystallized with an organic cation. Luminescent hybrid organic-inorganic halides with octahedral coordination of $\mathrm{Sb}$ (III) remain understudied, whereas fully inorganic compounds show very limited structural engineerability. We show that the host-guest complexation of alkali metal cations with crown ethers fosters the formation of zero-dimensional $\mathrm{Sb}(\mathrm{III})$ halides and allows for adjusting the

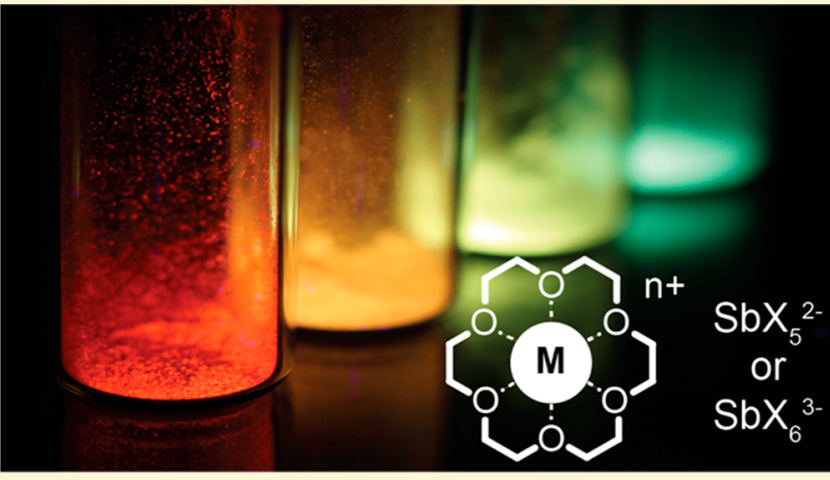
coordination number ( 5 or 6 ). The obtained compounds exhibit bright photoluminescence with quantum yields of up to $89 \%$ originating from self-trapped excitons, with emission energies, Stokes shifts, and luminescence lifetimes finely-adjustable by structural engineering. A combination of environmental stability and strong, intrinsic temperature-dependence of the luminescence lifetimes in the nanosecond-to-microsecond range nominate these compounds as highly potent luminophores for remote thermometry and thermography owing to their sensitivity range of $200-450 \mathrm{~K}$ and high specific sensitivities of $0.04{ }^{\circ} \mathrm{C}^{-1}$.

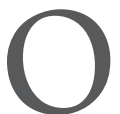

rganic-inorganic hybrid compounds with structurally and electronically isolated (OD) metal halide anions and organic cations are gaining increasing attention since the past few years. ${ }^{1-5}$ The interest stems from their color-tunable emission from self-trapped excitons (STE), often with high photoluminescence quantum yield (PL QY) already at room temperature (RT). Bright STE emission is commonly reported for metal ions with $\mathrm{ns}^{2}$ electron configuration, for example, $\mathrm{Ge}^{2+}, \mathrm{Sn}^{2+}, \mathrm{Pb}^{2+}, \mathrm{Sb}^{3+}, \mathrm{Bi}^{3+}, \mathrm{Te}^{4+}$, and $\mathrm{Cu}^{+}$with halide ligands. ${ }^{6-23}$ Since STE is the result of exciton interaction with lattice and large structural reorganization in the excited state, emission in prevailing majority of such materials is spectrally broad and exhibits large Stokes shift. Depending upon the depth of trapping, PL QY of up to $100 \%$ at RT is not uncommon and, unlike, for example, semiconductor quantum dots, PL QY is rather insensitive to the surface states and density of carriers and traps. At present, STE emissive halides are researched for applications in solid-state lighting, ${ }^{24,25}$ remote thermography, ${ }^{26}$ and X-ray scintillation. ${ }^{8,27}$

Generally, the coordination of $\mathrm{ns}^{2}$ ions by halides adopts diverse geometries, such as pyramidal, tetrahedral, disphenoi- dal, square pyramidal, and octahedral, which, in turn, determine the luminescence characteristics. The same metal ion may assume several of these coordinations and rational control of the preferred structure remains a formidable challenge. While adjusting the choice of bulky organic cations, typically quaternary ammonium or phosphonium salts, seems to offer a vast space for structure engineering, the outcome of such trials remains rather unpredictable with regard to the resulting coordination geometry. In this study, we sought of devising an alternative structure engineering strategy and showcase it for one specific $\mathrm{ns}^{2}$-ion case- $\mathrm{Sb}$ (III) halides. The latter are appealing for their environmental stability and low toxicity. We also note that hybrid $\mathrm{Sb}$ (III) halides, all comprising $\mathrm{SbX}_{5}^{2-}$ anion, are known to exhibit bright PL at

Received: April 26, 2020

Accepted: June 17, 2020

Published: June 17, 2020

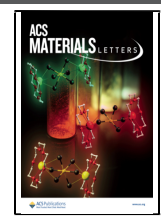


A Square pyramidal coordination

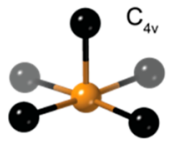

$\mathrm{SbX}_{5}^{2-}$

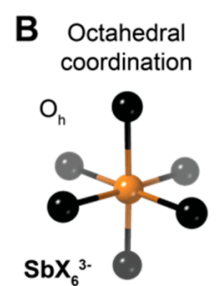

C

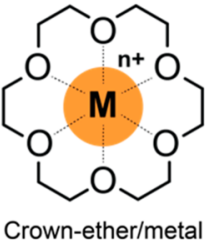

complex cation

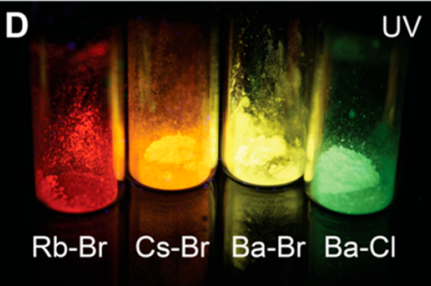

Figure 1. (A) Square pyramidal coordination of $\mathrm{Sb}^{3+}$ ion with $C_{4 v}$ point symmetry. (B) Octahedral coordination of $\mathrm{Sb}^{3+}$ ion with $\mathrm{O}_{h}$ point symmetry. (C) General chemical formula of the 18-crown-6 complex with alkali or alkaline-earth metal ions. (D) Photo of several obtained oD $\mathrm{Sb}(\mathrm{III})$ halide compounds with a complex crown-ether/metal cation, namely, $\left[\mathrm{C} @ \mathrm{Rb}_{2} \mathrm{SbBr}_{5},[\mathrm{C} @ \mathrm{Cs}]_{2} \mathrm{CsSbBr}{ }_{6},[\mathrm{C} @\right.$ $\mathrm{Ba}]_{4}\left[\mathrm{SbBr}_{6}\right]_{2}\left[\mathrm{Sb}_{2} \mathrm{Br}_{8}\right]$, and $\left[\mathrm{C} @ \mathrm{Ba}_{4}\left[\mathrm{SbCl}_{6}\right]_{2}\left[\mathrm{Sb}_{2} \mathrm{Cl}_{8}\right]\right.$ under $\mathrm{UV}(365 \mathrm{~nm})$ excitation.
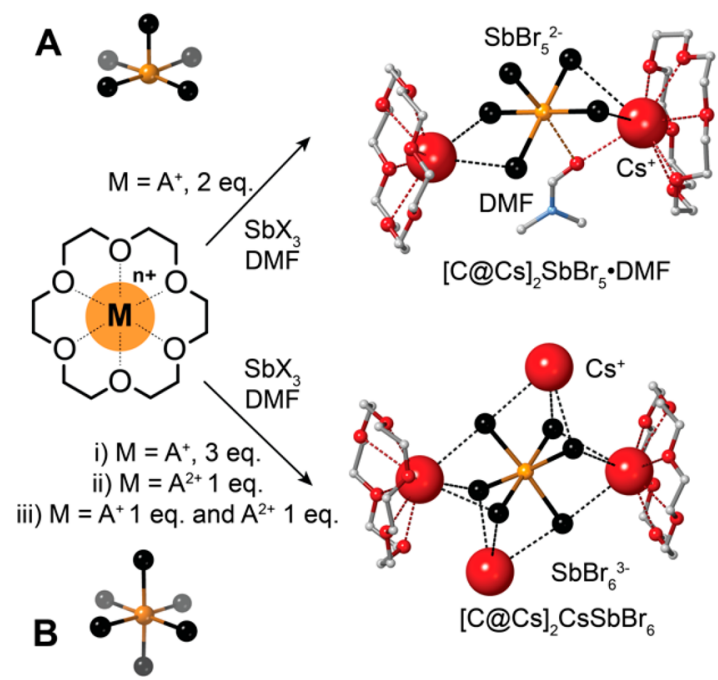

$[\mathrm{C} @ \mathrm{Cs}]_{2} \mathrm{SbBr}_{5} \cdot \mathrm{DMF}$

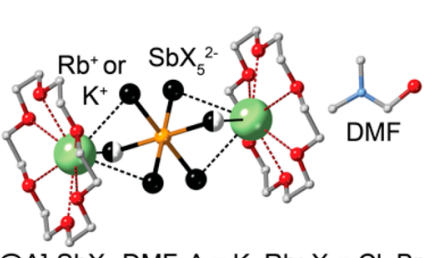

$\left[\mathrm{C} @ \mathrm{~A}_{2} \mathrm{SbX}_{5} \cdot \mathrm{DMF}, \mathrm{A}=\mathrm{K}, \mathrm{Rb} ; \mathrm{X}=\mathrm{Cl}, \mathrm{Br}\right.$
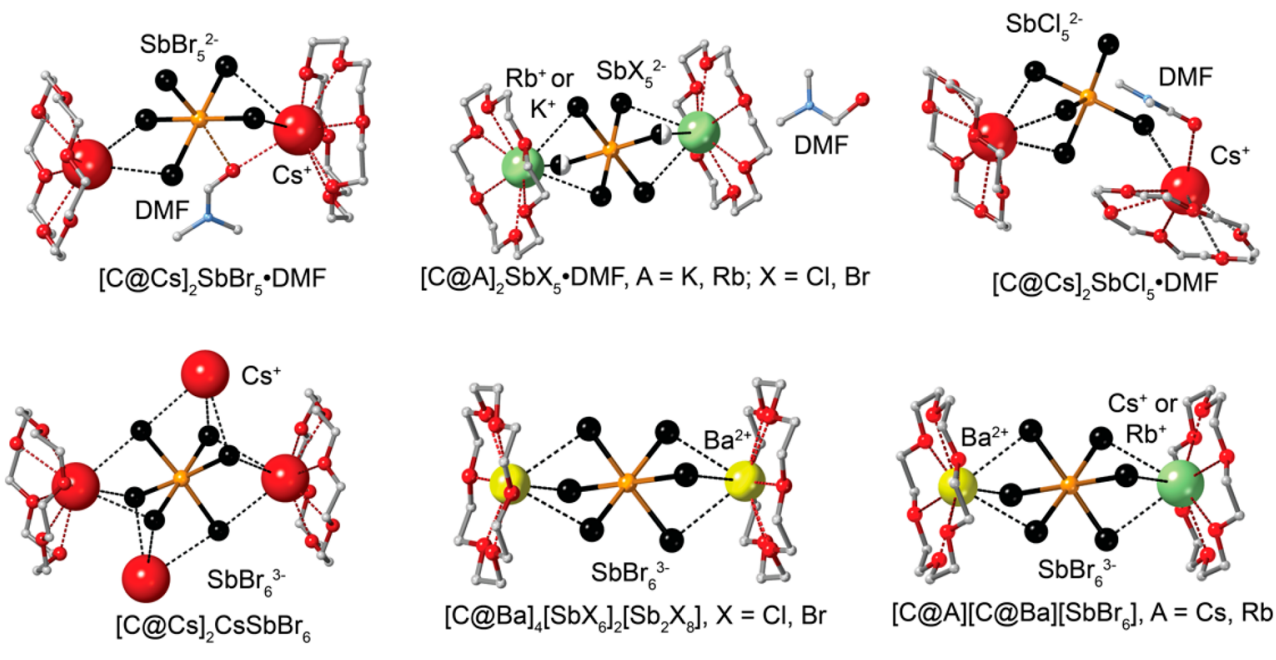

Figure 2. (A) Synthetic approach towards obtaining compounds with $\mathrm{SbX}_{5}{ }^{2-}$ anionic species that results in various crystal structures motives (half-filled atoms represent $50 \%$ static disorder). (B) Several synthetic approaches that result in $\mathrm{SbX}_{6}{ }^{3-}$ anionic species and local geometry of the obtained compounds.

RT. ${ }^{16,28-32}$ On the other hand, fully inorganic $\mathrm{Sb}$ halides, such as $\mathrm{A}_{3} \mathrm{Sb}_{2} \mathrm{X}_{9}$ (where $\mathrm{M}=\mathrm{Rb}$, Cs, methylammonium, $\mathrm{X}=\mathrm{Cl}, \mathrm{Br}$, $\mathrm{I})$, do not yield discrete $\mathrm{OD}$ anions, but rather condensed, nonor poorly luminescent structures (dimers, 1D-chains, 2Dlayers). ${ }^{33-36}$ By adopting a well-known supramolecular concept of host-guest coordination of alkali and alkaline earth metal cations $\left(\mathrm{Cs}^{+}, \mathrm{Rb}^{+}, \mathrm{Ba}^{2+}\right.$, etc. $)$ with crown ethers, we could deliberately form either $\mathrm{SbX}_{5}{ }^{2-}$ or $\mathrm{SbX}_{6}{ }^{3-}$ ions. We have then crystallized a library of Sb-halides, with bright PL spanning the visible spectral range, and rationalized their PL properties considering the STE geometries in relation to their crystal structures. We also show that some of these halides, such as $[\mathrm{C} @ \mathrm{Ba}]_{4}\left[\mathrm{SbCl}_{6}\right]_{2}\left[\mathrm{Sb}_{2} \mathrm{Cl}_{8}\right],[\mathrm{C} @ \mathrm{Ba}]_{4}\left[\mathrm{SbBr}_{6}\right]_{2}\left[\mathrm{Sb}_{2} \mathrm{Br}_{8}\right]$, [C@Cs $]_{2} \mathrm{CsSbBr}_{6},[\mathrm{C} @ \mathrm{Rb}]_{2} \mathrm{SbBr}_{5}$ (with C being 18-crown-6), are promising thermoluminophores for applications in remote thermometry and thermography. ${ }^{26}$

Typical 0D hybrids feature $\mathrm{SbX}_{5}{ }^{2-}$ square pyramidal anions (Figure 1A). ${ }^{16,28-31,37,38}$ Discrete $\mathrm{SbX}_{6}{ }^{3-}$ octahedra (Figure 1B) are very seldom. ${ }^{38-41}$ Indeed, common organic cations are single charged $\left(\mathrm{Ph}_{4} \mathrm{P}^{+}, \mathrm{Et}_{4} \mathrm{~N}^{+}\right.$, etc. $)$and, hence, favor the lower charge on the halometalate anion. Our supramolecular approach readily serves both needs-controlled bulkiness and adjustable charge of the cation-as 18-crown- 6 ether readily coordinates alkali metal $\left(\mathrm{K}^{+}, \mathrm{Rb}^{+}, \mathrm{Cs}^{+}\right)$or alkaline earth metal $\left(\mathrm{Ba}^{2+}\right.$, Figure $\left.1 \mathrm{C}\right)$. Consequently, the coordination number around $\mathrm{Sb}$ (III) could be adjusted in the obtained compounds (Figure 2), concomitantly with the tailoring of the emission color. The approach also allows for combining differently charged inorganic cations in one structure, such as in $[\mathrm{C} @ \mathrm{Rb}][\mathrm{C} @ \mathrm{Ba}]\left[\mathrm{SbBr}_{6}\right]$ and $[\mathrm{C} @ \mathrm{Cs}][\mathrm{C} @ \mathrm{Ba}]\left[\mathrm{SbBr}_{6}\right]$ (Figure 2). In the following, we correlate the structure of the obtained compounds with the PL characteristics. In this context, we would like to emphasize that such host-guest chemistry engineering is interesting not only for controlling formability of specific halometalate ions, as in this study, but also because it can alter the optical and other properties in non-obvious ways. An example of the latter is [K(dibenzo-18crown-6) $]_{2} \mathrm{MnX}_{4}(\mathrm{X}=\mathrm{Cl}, \mathrm{Br})$, which exhibits circularly polarized emission owing to the difference in the symmetry of the crystal structure. ${ }^{42}$ We would also note that the supramolecular approach, despite integration of crown molecules, still leads to a rather compact packing of Sb-halide anions. For instance, the molar volume of $[\mathrm{C} @ \mathrm{Rb}]_{2} \mathrm{SbCl}_{5}$ is just $70 \%$ of that of $\left(\mathrm{Ph}_{4} \mathrm{P}\right)_{2} \mathrm{SbCl}_{5}\left(457 \mathrm{vs} 655 \mathrm{~cm}^{3} \mathrm{~mol}^{-1}\right.$, respectively), while both compounds exhibit high $\mathrm{PL} \mathrm{QY}$.

Two equivalents of single-charged complex cations result solely in square-pyramidal $\mathrm{SbX}_{5}{ }^{2-}$ (Figure $2 \mathrm{~A}$ ). The $\mathrm{SbBr}_{5}{ }^{2-}$ anion is "sandwiched" between two crown-ether metal complexes, yielding short distances between halide ions and inorganic cations. The crystal structure usually contains also solvent molecules, which is typical also for many $\mathrm{OD}$ organicinorganic hybrids. There are also several modes for solvent molecule coordination, of which one could highlight the 

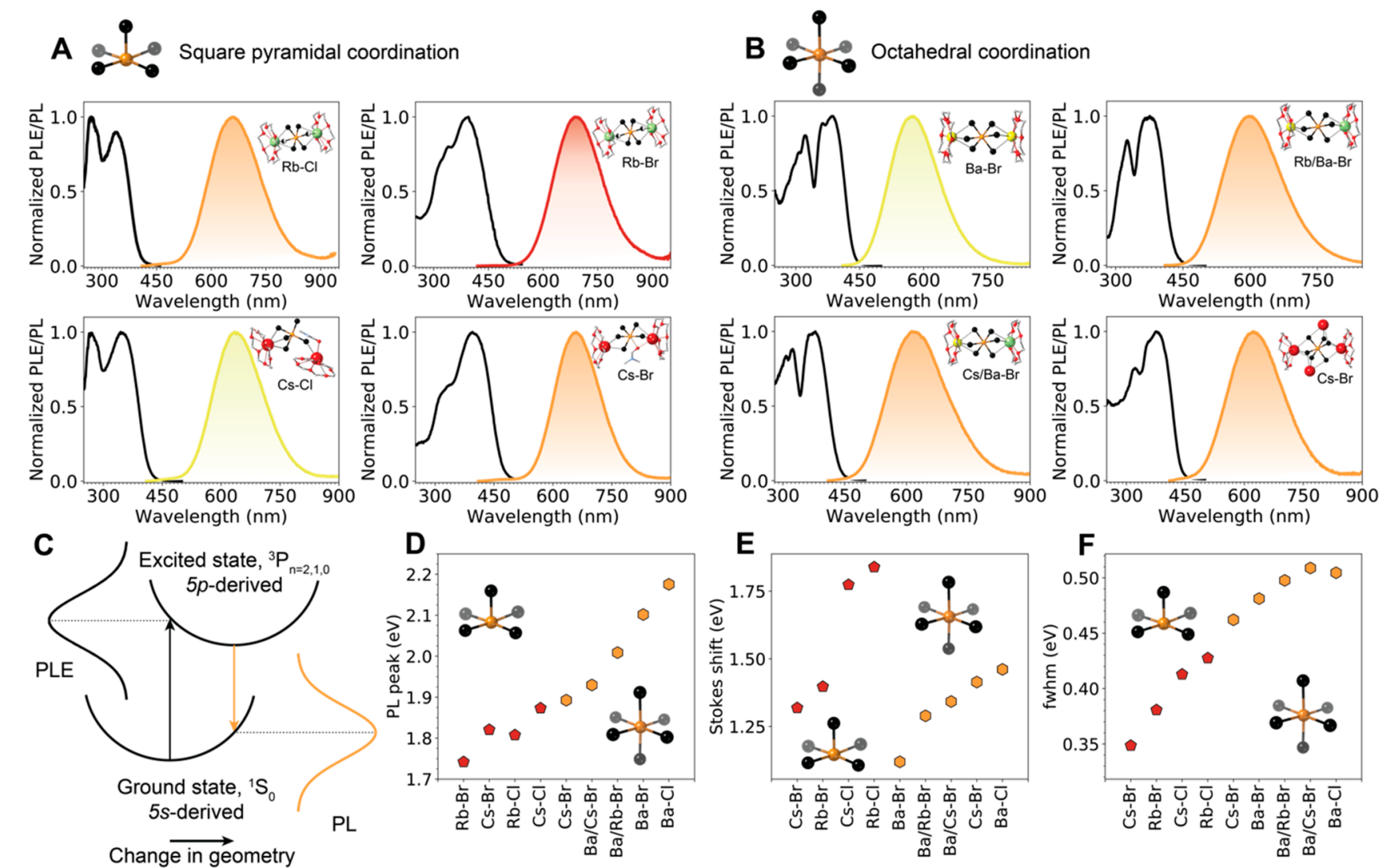

Figure 3. (A) Normalized PLE and PL spectra of the compounds with square pyramidal coordination, $[\mathrm{C} @ A]_{2} \mathrm{SbX}$, where $\mathrm{A}=\mathrm{Rb}, \mathrm{Cs}$ and $\mathrm{X}$ $=\mathrm{Cl}$, Br. (B) Normalized PLE and PL spectra of the compounds with octahedral coordination, $\left[\mathrm{C} @ \mathrm{Ba}_{4}\left[\mathrm{SbBr}_{6}\right]_{2}\left[\mathrm{Sb}_{2} \mathrm{Br}_{8}\right],[\mathrm{C} @ \mathrm{Rb}][\mathrm{C} @\right.$ $\mathrm{Ba}]\left[\mathrm{SbBr}_{6}\right],[\mathrm{C} @ \mathrm{Cs}][\mathrm{C} @ \mathrm{Ba}]\left[\mathrm{SbBr}_{6}\right]$, and $[\mathrm{C} @ \mathrm{Cs}]_{2} \mathrm{CsSbBr}_{6}$. (C) Single-coordinate diagram depicting the excitation and emission processes from of the localized states. (D) PL peak, (E) Stokes shift, and (F) fwhm trends across different compounds at RT.

appearance of an oxygen atom from DMF molecule in the $\mathrm{Sb}$ coordination sphere ([C@Cs $\left.]_{2} \mathrm{SbBr}_{5} \cdot \mathrm{DMF}\right)$.

Discrete $\mathrm{SbX}_{6}{ }^{3-}$ octahedra were successfully obtained in several ways, namely by having (i) three equivalents of $\mathrm{A}^{+}$ cation, (ii) one equivalent of $\mathrm{A}^{2+}$, and (iii) one equivalent of each $\mathrm{A}^{2+}$ and $\mathrm{A}^{+}$(see Supporting Information, SI, for details). The first scenario results in a compound [C@Cs $]_{2} \mathrm{CsSbBr}_{6}$, where only two Cs atoms form complex with the crown ether. This also leads to the packing of [C@Cs $]_{2} \mathrm{CsSbBr}_{6}$ units in $1 \mathrm{D}$ fashion along the $b$ direction (Figure $\mathrm{S} 1$ ). This compound can be viewed as the first antimony-based hybrid in between fully inorganic (e.g., $\mathrm{Cs}_{3} \mathrm{Sb}_{2} \mathrm{Br}_{9}$ ) and compounds with organic cations. Scenario 2 yields compounds $[\mathrm{C@Ba}]_{4}\left[\mathrm{SbX}_{6}\right]_{2}\left[\mathrm{Sb}_{2} \mathrm{X}_{8}\right]$ $(\mathrm{X}=\mathrm{Cl}$ or $\mathrm{Br}$, isostructural compounds, Figure S2D) that features two $0 \mathrm{D} \mathrm{Sb}$ (III) halide species (Figure S3, partially shown in Figure 2). Apart from octahedral species (Figure $\mathrm{S} 3 \mathrm{~B})$, the overall charge neutrality is maintained by the dimer $\left[\mathrm{Sb}_{2} \mathrm{Br}_{8}\right]^{2-}$ species, which are built from two edge-sharing square pyramids (Figure S3C). Such edge-sharing $\mathrm{SbX}_{5}$ pyramids are known from the literature; however, they display no emission at RT. ${ }^{43}$ The scenario (iii) yields compounds $[\mathrm{C} @ \mathrm{Rb}][\mathrm{C} @ \mathrm{Ba}]\left[\mathrm{SbBr}_{6}\right]$ and $[\mathrm{C} @ \mathrm{Cs}][\mathrm{C} @ \mathrm{Ba}]\left[\mathrm{SbBr}_{6}\right]$, crystallizing in a high symmetry space group, $R \overline{3} a$. This is due to the fact that the cumulative positive charge of $3+$ from two cations is matching the negative charge of the anionic species. Crystal data and structure refinement details for all crystallized compounds as well as photos of crystalline samples can be found in Tables S1-9 and Figure S4.
Having a library of novel $\mathrm{OD} \mathrm{Sb}$ (III)-halides allows for correlating the anion geometry and other structural details with the PL characteristics (see optical properties on Figures 3 and S5-S7 and in Table S10). All obtained compounds are luminescent at RT, exhibiting broad emission bands (full width at half maxima, fwhm, of 350-510 meV) and large Stokes shifts for both square pyramidal (Figure 3A) or octahedral (Figure 3B) anions. While PL bands are located at 550-750 nm, PL excitation (PLE) spectra appears below $450 \mathrm{~nm}$ and contains several bands. The optical properties of isolated $\mathrm{Sb}^{3+}$ ions, as well as any $\mathrm{ns}^{2}$ ion, can be described in terms of transitions between the states derived from $\mathrm{Sb} 5 \mathrm{~s}$ and $5 \mathrm{p}$ states hybridized with ligand p states. Despite significant contributions from the ligand atomic orbitals, some features of the PLE and PL can still be simply interpreted using Seitz model. ${ }^{44,45}$ In this model, the ground state $\left(5 \mathrm{~s}^{2}\right)$ is a singlet denoted with atomic term ${ }^{1} \mathrm{~S}_{0}$ and the excited states $\left(5 s^{1} 5 p^{1}\right)$ consist of triplets and a singlet with corresponding atomic terms ${ }^{3} \mathrm{P}_{0},{ }^{3} \mathrm{P}_{1},{ }^{3} \mathrm{P}_{2}$ and ${ }^{1} \mathrm{P}_{1}$, respectively.

For $0 \mathrm{D} \mathrm{ns}^{2}$ group 4 metal halides, it has been recently demonstrated that various RT emission bands and their components can be ascribed to transitions between these states. $^{8}$ A similar study has also been conducted on $\left(\mathrm{Et}_{4} \mathrm{~N}\right)_{2} \mathrm{SbCl}_{5}$ proving that the model is valid in case of $\mathrm{Sb}^{29}$ Seitz model can also be extended with molecular orbital theory to account for the ligand field influence. ${ }^{46}$ Upon hybridization with molecular orbitals of the ligands, resulting molecular states are derived from respective atomic states $\left({ }^{3} \mathrm{P}_{0},{ }^{3} \mathrm{P}_{1},{ }^{3} \mathrm{P}_{2}\right.$, and ${ }^{1} \mathrm{P}_{1}$ ) and preserve multiplicity (singlet or triplet). 
A
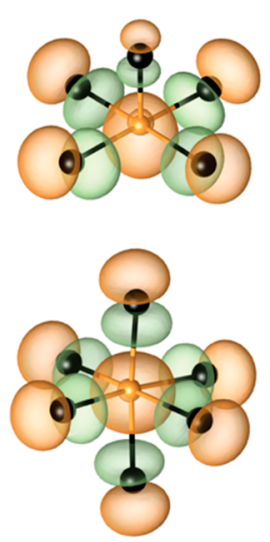

HOMO

$\sigma^{*}$ character
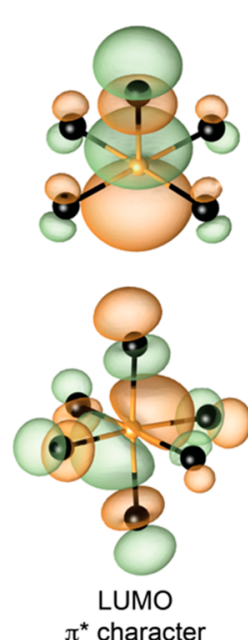
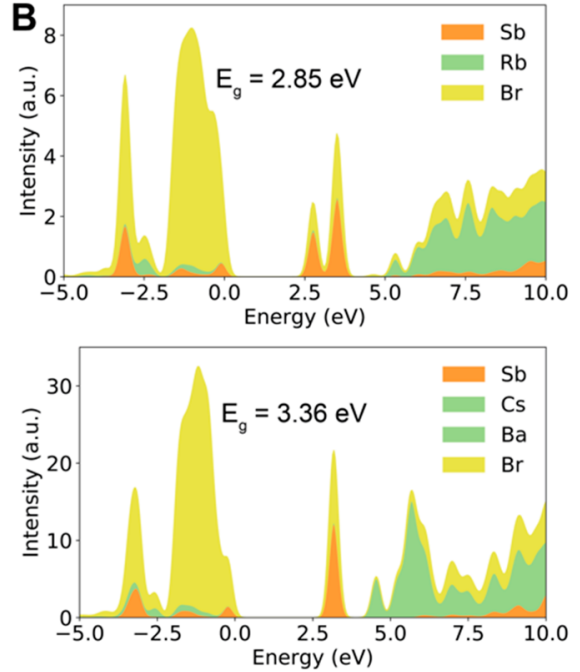

C

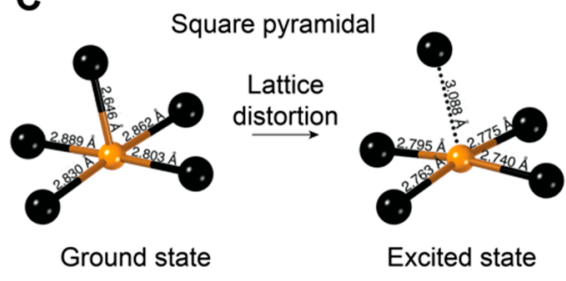

Ground state

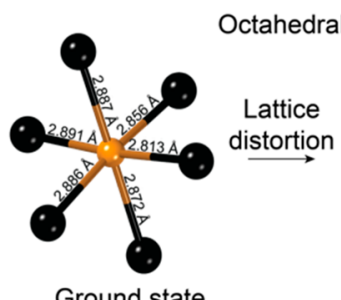

Ground state

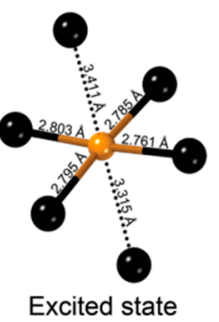

Figure 4. (A) Atomically projected molecular orbitals for $\mathrm{SbX}_{5}$ (top) and $\mathrm{SbBr}_{6}$ (bottom) molecular geometries. The $\mathrm{HOMO}$ in both cases has antibonding $\sigma^{*}$ nature, whereas LUMO has antibonding $\pi^{*}$ nature. (B) Cumulative DOS of $[\mathrm{C} @ \mathrm{Rb}]_{2} \mathrm{SbBr}_{5}($ top) and $[\mathrm{C} @ \mathrm{Cs}][\mathrm{C} @$ $\mathrm{Ba}]\left[\mathrm{SbBr}_{6}\right]$ (bottom); other atomic contributions $(\mathrm{O}, \mathrm{C}, \mathrm{H}$, etc.) are omitted for clarity. (C) The distortion of the ground state molecular geometry in the excited state for $\mathrm{SbX}_{5}$ (top) and $\mathrm{SbX}_{6}$ (bottom) geometries showcasing an axial metal halide bond extension.

Increasingly common in the recent literature is to outline the optical properties of the STE in $\mathrm{ns}^{2}$ metal halides using a simple configurational diagram (Figure 3C). In this diagram, the ground and excited states are represented by potential energy curves. The abscissa axis in this diagram represents the change in geometry: zero point is taken as the ground state equilibrium geometry. The further on this coordinate is the excited state minimum, the bigger is the difference between the ground and excited-state geometries. This depiction readily visualizes the large PL Stokes shift. $\mathrm{SbX}_{5}{ }^{2-}$ ions display emission shifted to the red region of the visible spectrum, unlike to emission from $\mathrm{SbX}_{6}{ }^{3-}$ occurring at higher energies. Likewise, also the PLE onset for $\mathrm{SbX}_{5}{ }^{2-}$ is found at lower energies. This suggests that higher coordination number leads to larger HOMO-LUMO gaps. For $\mathrm{SbX}_{5}{ }^{2-}$, the Stokes shift is much larger for chlorides than bromides (Figure 3E), which results from greater structural rearrangement in the excited state for chlorides. Interestingly, RT broadening has two contributors: intrinsic, related to the variation in the local environment of different emitting centers and extrinsic, caused by the energy states broadening at higher temperatures due to activation of vibrational states. The trends obtained from experimental data evidence that square pyramidal coordination results in narrower emission as compared to octahedral. The fwhm in $\mathrm{SbX}_{5}{ }^{2-}$ compounds scale with the average $\mathrm{Sb}-\mathrm{X}$ bond length for the same halide (Figure S8), which could be explained by stronger hybridization between the central ion and ligands causing larger thermal broadening. At the same time, no such correlation with the average bond length could be seen for $\mathrm{SbX}_{6}{ }^{3-}$, suggesting a dynamic effect discussed below.

Further insight into the structure-property relation was obtained with the aid of Density Functional Theory (DFT) calculations as implemented in the cp2k code (see SI for details). We have performed both ground state and excited state geometry optimization. Generally, the electronic structure of all $\mathrm{ns}^{2}$ metal halides is similar in terms of atomic contributions. Overall, the electronic structure is highly localized, and the typical band structure diagram features flat non-dispersed bands (Figure S9). Because of this, we only concentrate on the analysis of the density of states (DOS). The highest occupied molecular orbital (HOMO) has an antibonding character and is derived from $S b-p$ and $X-p$ states, while the lowest unoccupied molecular orbital (LUMO) also has an antibonding character and is derived from $\mathrm{Sb}-\mathrm{p}$ and $\mathrm{X}$-p states. A significant difference between square pyramidal and octahedral coordination is the stereoactivity of the lone pair (Figure 4A). In the case of $\mathrm{SbX}_{5}$, the lone pair occupies a vacant axial position, stabilizing the square pyramidal geometry. There is no apparent evidence of the lone pair stereoactivity in $\mathrm{SbX}_{6}{ }^{3-}$ from the structure determination (systematic axial bond elongation or $\mathrm{Sb}$ atom off-centering for stabilizing HOMO, e.g., first and second-order Janh-Teller distortions). ${ }^{46}$ A less obvious player could be a dynamic distortion, ${ }^{47,48}$ which may be a hidden cause for a broader emission from $\mathrm{SbX}_{6}$ compounds. Figures $4 \mathrm{~B}$ and S10 displays typical element- and orbital-decomposed DOS plots for $\mathrm{SbX}_{5}$ and $\mathrm{SbX}_{6}$.

In accordance with experimental PLE data, calculated HOMO-LUMO gap is smaller for square pyramidal geometry. $\mathrm{SbX}_{5} \mathrm{LUMO}$ has two nondegenerate energy states as expected for $C_{4 v}$ symmetry, whereas three excited states in $\mathrm{SbX}_{6}$ LUMO are all degenerate due to $\mathrm{O}_{h}$ symmetry. In agreement, $\mathrm{SbCl}_{5}$ compounds typically exhibit one additional emission band in the blue region, unlike $\mathrm{SbCl}_{6}{ }^{3-29,39}$ Typically for an STE, a large structural change occurs once electron is promoted to LUMO. This structural change has been previously accessed with DFT for various OD Sn and Sb emitters. ${ }^{8,10-12,16,49} \mathrm{We}$ have simulated the structural change by relaxing the triplet geometry in unrestricted Kohn-Sham method as implemented in the cp2k code (details can be found in SI). Figure $4 \mathrm{C}$ depicts the geometry change in the excited state. In both $\mathrm{SbX}_{5}$ and $\mathrm{SbX}_{6}$, the axial $\mathrm{Sb}-\mathrm{X}$ bonds are elongating by the significant value of about $0.5 \AA$, while the equatorial $\mathrm{Sb}-\mathrm{X}$ bonds are shortened by about $0.1 \AA$. In addition, in $\mathrm{SbX}_{5}$, there is a unique mode of distortion: out-of-plane movement of $\mathrm{Sb}$ atom above the axial halides plane (Figure S11). While the relative change in bond length is comparable for $\mathrm{Cl}$ and $\mathrm{Br}$ ligands, the $\mathrm{Sb}$ displacement is stronger for $\mathrm{Cl}$, explaining a larger difference in Stokes shift for $\mathrm{SbBr}_{5}$ and $\mathrm{SbCl}_{5}$ (from 1.4 
to $1.8 \mathrm{eV})$ in comparison to $\mathrm{SbBr}_{6}$ and $\mathrm{SbCl}_{6}(1.45$ to $1.4-1.3$ $\mathrm{eV})$. The energy states of both isolated octahedral and dimer units in $[\mathrm{C} @ \mathrm{Ba}]_{4}\left[\mathrm{SbBr}_{6}\right]_{2}\left[\mathrm{Sb}_{2} \mathrm{Br}_{8}\right]$ lie close together in DOS (Figure S12). The HOMO states that originate from $\mathrm{SbBr}_{6}{ }^{3-}$ are at $0.59 \mathrm{eV}$ in the DOS, while LUMO is at $3.95 \mathrm{eV}$. The HOMO-LUMO difference equates to $3.36 \mathrm{eV}(370 \mathrm{~nm})$. For the $\mathrm{Sb}_{2} \mathrm{Br}_{8}$ dimeric unit, HOMO-LUMO gap is $2.95 \mathrm{eV}$ (420 $\mathrm{nm})$.

The onset of the experimental PLE spectrum is at $3.22 \mathrm{eV}$, rather close to the HOMO-LUMO gap of $\mathrm{SbBr}_{6}$. In the literature, $\mathrm{Sb}_{2} \mathrm{Br}_{8}{ }^{2-}$ units were found to luminesce at cryogenic temperatures. ${ }^{43}$ Taken together, these considerations suggest that the RT emission in $[\mathrm{C} @ B]_{4}\left[\mathrm{SbBr}_{6}\right]_{2}\left[\mathrm{Sb}_{2} \mathrm{Br}_{8}\right]$ can be assigned to $\mathrm{SbBr}_{6}{ }^{3-}$ centers. DFT analysis also points to insignificant electronic hybridization with the DMF solvent molecule, commonly found to coordinate $\mathrm{SbBr}_{5}$ anion in one of the obtained compounds (Figure S13).

We have recently demonstrated that STE-emissive $\mathrm{ns}^{2}$ metal halides are highly promising luminophores for remote thermometry and thermography, as demonstrated with $\mathrm{Cs}_{4} \mathrm{SnX}_{6}$ and $\mathrm{Sn}(\mathrm{II})$ hybrids. ${ }^{26}$ Luminescent $\mathrm{Sb}$ (III) halides make for a highly appealing alternative due to their much higher environmental stability ( $\mathrm{Sn}^{2+}$ readily oxidizes). A candidate STE emitter must exhibit the following PL characteristics: strong temperature-dependence of the PL lifetime in the desired (for sensing) temperature range and variation of this lifetime in the nanosecond-to-microsecond range. The measured PL decays (Figure $5 \mathrm{~A}$ and $\mathrm{B}$; see also
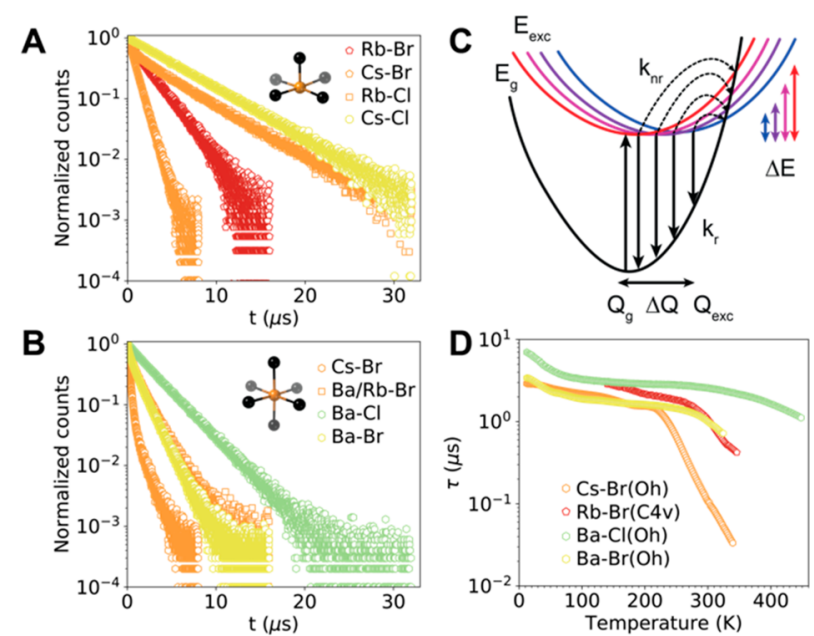

Figure 5. RT emission decay curves ( $355 \mathrm{~nm}$ laser excitation) for the selected compounds with (A) square pyramidal and (B) octahedral coordinations. (C) Single coordinate diagram model to account for the non-radiative $\left(k_{\mathrm{nr}}\right)$ exciton recombination pathway, showing excited states with different Stokes shift, corresponding to different temperatures of PL quenching. (D) Temperaturedependent average radiative decay time $\tau$ dependencies for the selected compounds: $[\mathrm{C} @ \mathrm{Ba}]_{4}\left[\mathrm{SbCl}_{6}\right]_{2}\left[\mathrm{Sb}_{2} \mathrm{Cl}_{8}\right]$ (green), [C@ $\mathrm{Ba}]_{4}\left[\mathrm{SbBr}_{6}\right]_{2}\left[\mathrm{Sb}_{2} \mathrm{Br}_{8}\right]$ (yellow), [C@Cs $]_{2} \mathrm{CsSbBr}_{6}$ (orange), and $[\mathrm{C} @ \mathrm{Rb}]_{2} \mathrm{SbBr}_{5}$ (red).

Table S11) can be fitted with either a monoexponential function or a biexponential with a shorter component. The corresponding radiative and nonradiative processes can be outlined with the configuration coordinate diagram (Figure 5C). The slower, radiative decay in this model $\left(k_{\mathrm{r}}\right)$ occurs from the center of the excited state parabola and the ground state. A competing, faster nonradiative decay path $\left(k_{\mathrm{nr}}\right)$ is a phonon- assisted de-trapping of the STE. This process has an activation barrier $\Delta E$ and, hence, accelerates at higher temperatures. Furthermore, such an increase in $k_{\mathrm{nr}}$ starts earlier (i.e., at lower temperatures) for compounds with larger Stokes shift (see a general correlation trend between the Stokes shifts in Table S10 and PL lifetimes at RT in Table S11). Consequently, at sufficiently low temperatures, STE-emitters shall ideally exhibit PL QY of $100 \%$ (in the absence of additional absorptive processes like the presence of impurities, etc., at the excitation wavelengths). At higher temperatures, there is a temperature range in which the $\mathrm{PL} \mathrm{QY}$ and measured PL lifetime $\left(\tau=\frac{1}{k_{\mathrm{r}}+k_{\mathrm{nr}}}\right)$ must rapidly drop. Remote measurement/ mapping of the PL lifetime by, for instance, TCSPC or timeof-flight techniques, is the physical basis for remote thermometry/thermography. Structure-engineering of STEemitters allows tuning of $\Delta E$ and hence the temperature range of PL lifetime sensitivity. Already RT values of PL QY and PL lifetime provide initial guidance as to the PL lifetime sensitivity range. For instance, moderate PL QY (20-60\%), along with a PL lifetime of $0.1-1 \mu \mathrm{s}$, may indicate a partially quenched state at RT, and hence, such a compound may be suited as a thermoluminophore in a temperature range of approximately $\mathrm{RT} \pm 50{ }^{\circ} \mathrm{C}$. A material with a near-unity RT PL QY and a long PL lifetime $(1-10 \mu \mathrm{s})$ is likely sensitive to the elevated temperatures (within its thermal durability window). Conversely, a compound with RT PL QY of just a few\% or less and PL lifetime of few tens of ns is expected to exhibit a sensitivity range upon cooling or even at cryogenic temperatures. For $\mathrm{Sb}-\mathrm{X}$ bond series, the iodides have the lowest vibrational frequency and are activated already at very low temperatures, thereby explaining why $\mathrm{SbI}_{5}{ }^{2-}$ or $\mathrm{SbI}_{6}{ }^{3-}$ compounds usually not emissive at RT. ${ }^{41,50}$ On the contrary, chlorides have the highest vibrational frequency (Figure S14), which means that RT modes, responsible for emission quenching, are not sufficiently populated and this results in almost unity PL QY at RT.

Figure 5D exemplifies PL lifetime vs $T$ dependencies, showing, for instance, that $[\mathrm{C} @ \mathrm{Cs}]_{2} \mathrm{CsSbBr}_{6}$ can measure temperature upon cooling, whereas $[\mathrm{C} @ \mathrm{Ba}]_{4}\left[\mathrm{SbCl}_{6}\right]_{2}\left[\mathrm{Sb}_{2} \mathrm{Cl}_{8}\right]$ is operational at higher temperatures. On the basis of these $\mathrm{PL}$ lifetime vs temperature curves, specific sensitivity $\alpha$ can be calculated (Figure S15), which is, for instance, up to $0.04{ }^{\circ} \mathrm{C}^{-1}$ for $[\mathrm{C} @ \mathrm{Cs}]_{2} \mathrm{CsSbBr}_{6}$. This value is comparable with $0.05{ }^{\circ} \mathrm{C}^{-1}$ for $\left(\mathrm{C}_{4} \mathrm{~N}_{2} \mathrm{H}_{14} \mathrm{I}\right)_{4} \mathrm{SnI}_{6}$ and $\mathrm{Cs}_{4} \mathrm{SnBr}_{6}$ compounds in our earlier study $^{26}$ and higher than that of commonly reported thermoluminophores $(0.005-0.030) .^{51}$

In conclusion, we have employed supramolecular chemistry strategy to selectively access a specific molecular geometry of antimony halide $0 \mathrm{D}$ centers, $\mathrm{SbX}_{5}$ or $\mathrm{SbX}_{6}$. This has enabled us to reveal the trends in compounds with a broad, largely Stokes shifted and highly efficient emission. The PL of synthesized compounds covers a major part of the visible spectrum (550$750 \mathrm{~nm}$ ), with large Stokes shifts from 1 to $2 \mathrm{eV}$, while RT PL QY varies from 11 to $89 \%$. Understanding the optical properties trends allows for the choice of the emitter, aiming for certain PL QY, Stokes shift, or spectral color of the emission. Furthermore, we have assessed the potential of such stable Sb-based emitters for a thermography application, revealing that by tuning the coordination and composition, thermoluminophores covering a broad temperature range (from $200 \mathrm{~K}$ to above $450 \mathrm{~K}$ ) with good specific sensitivity (up to $0.04{ }^{\circ} \mathrm{C}^{-1}$ ) were designed and synthesized. 


\section{ASSOCIATED CONTENT}

\section{(I) Supporting Information}

The Supporting Information is available free of charge at https://pubs.acs.org/doi/10.1021/acsmaterialslett.0c00174.

Materials, synthesis, characterization, computational details, packing in $[\mathrm{C} @ \mathrm{Cs}]_{2} \mathrm{CsSbBr}_{6}$, experimental and simulated PXRD patterns, packing of the $[\mathrm{C} @$ $\mathrm{Ba}]_{4}\left[\mathrm{SbBr}_{6}\right]_{2}\left[\mathrm{Sb}_{2} \mathrm{Br}_{8}\right]$, optical microscope images of crystalline samples, PL and PLE of the [C@ $\mathrm{Ba}]_{4}\left[\mathrm{SbCl}_{6}\right]_{2}\left[\mathrm{Sb}_{2} \mathrm{Cl}_{8}\right]$, comparison of PLE and Kubelka-Munk spectra, 2D PL/PLE maps, optical properties (PL peak position, fwhm, PLE peak, Stokes shift, PLQY) for the obtained antimony(III) halide hybrids, PL fwhm dependence on the average $\mathrm{Sb}-\mathrm{X}$ bond, orbitalprojected band structure plots, orbital-decomposed cumulative DOS, structural change from ground to the excited state, DOS of $[\mathrm{C} @ B]_{4}\left[\mathrm{SbBr}_{6}\right]_{2}\left[\mathrm{Sb}_{2} \mathrm{Br}_{8}\right]$ and [C@Cs $]_{2} \mathrm{SbBr}_{5}$, results of mono- or biexponential fitting of the RT decay times, Raman spectra of [C@ $\mathrm{Ba}]_{4}\left[\mathrm{SbCl}_{6}\right]_{2}\left[\mathrm{Sb}_{2} \mathrm{Cl}_{8}\right]$ and $[\mathrm{C} @ B]_{4}\left[\mathrm{SbBr}_{6}\right]_{2}\left[\mathrm{Sb}_{2} \mathrm{Br}_{8}\right]$, specific sensitivity, and photostability test (PDF)

Crystallographic data for $[\mathrm{C} @ \mathrm{~K}]_{2} \mathrm{SbBr}_{5}, \quad[\mathrm{C} @$ $\mathrm{Ba}]_{4}\left[\mathrm{SbBr}_{6}\right]_{2}\left[\mathrm{Sb}_{2} \mathrm{Br}_{8}\right],[\mathrm{C} @ \mathrm{Cs}][\mathrm{C} @ \mathrm{Ba}]\left[\mathrm{SbBr}_{6}\right], \quad[\mathrm{C} @$ $\mathrm{Rb}]_{2} \mathrm{SbCl}_{5}, \quad[\mathrm{C} @ \mathrm{Cs}]_{2} \mathrm{SbCl}_{5},[\mathrm{C} @ \mathrm{Rb}]_{2} \mathrm{SbBr}_{5}, \quad[\mathrm{C} @$ $\mathrm{Cs}]_{2} \mathrm{SbBr}_{5}$, [C@Cs $]_{2} \mathrm{CsSbBr}_{6}$, and [C@Rb][C@Ba]$\left[\mathrm{SbBr}_{6}\right]$ (CCDC 1997955) (ZIP)

\section{AUTHOR INFORMATION}

\section{Corresponding Author}

Maksym V. Kovalenko - Laboratory of Inorganic Chemistry, Department of Chemistry and Applied Bioscience, ETH Zürich, CH-8093 Zürich, Switzerland; Laboratory for Thin Films and Photovoltaics, Empa-Swiss Federal Laboratories for Materials Science and Technology, CH-8600 Dübendorf, Switzerland; ○ orcid.org/0000-0002-6396-8938; Email: mvkovalenko@ ethz.ch

\section{Authors}

Viktoriia Morad - Laboratory of Inorganic Chemistry, Department of Chemistry and Applied Bioscience, ETH Zürich, CH-8093 Zürich, Switzerland; Laboratory for Thin Films and Photovoltaics, Empa-Swiss Federal Laboratories for Materials Science and Technology, CH-8600 Dübendorf, Switzerland; (1) orcid.org/0000-0002-9712-0433

Sergii Yakunin - Laboratory of Inorganic Chemistry, Department of Chemistry and Applied Bioscience, ETH Zürich, CH-8093 Zürich, Switzerland; @ orcid.org/0000-0002-64090565

Complete contact information is available at:

https://pubs.acs.org/10.1021/acsmaterialslett.0c00174

\section{Notes}

The authors declare no competing financial interest. Experimental and computational methods and crystallographic data (CIF files) for [C@Cs $]_{2} \mathrm{SbBr}_{5},[\mathrm{C} @ \mathrm{Cs}]_{2} \mathrm{SbCl}_{5}$, [C@ $\mathrm{Rb}]_{2} \mathrm{SbBr}_{5},[\mathrm{C} @ \mathrm{Rb}]_{2} \mathrm{SbCl}_{5},[\mathrm{C} @ \mathrm{Ba}]_{4}\left[\mathrm{SbBr}_{6}\right]_{2}\left[\mathrm{Sb}_{2} \mathrm{Br}_{8}\right],[\mathrm{C} @$ $\mathrm{Rb}][\mathrm{C} @ \mathrm{Ba}]\left[\mathrm{SbBr}_{6}\right], \quad[\mathrm{C} @ \mathrm{Cs}][\mathrm{C} @ \mathrm{Ba}]\left[\mathrm{SbBr}_{6}\right], \quad[\mathrm{C} @$ $\mathrm{Cs}]_{2} \mathrm{CsSbBr}_{6}$ and $[\mathrm{C} @ \mathrm{~K}]_{2} \mathrm{SbBr}_{5}$ are deposited in the Cambridge Crystallographic Data Centre database (CCDC) with the following deposition numbers: 1997940, 1998078, 1997957, 1998034, 1998064, 1997955, 1998033, 1997953, 1998071.

\section{ACKNOWLEDGMENTS}

The authors are indebted to Dr. Yevhen Shynkarenko for assistance with PL QY measurements, Dr. Michael Woerle for assistance with crystal structure solution, and Dr. Kyle Mccall for performing Raman experiments. The authors acknowledge the support of the Scientific Center for Optical and Electron Microscopy (ScopeM) of the Swiss Federal Institute of Technology (ETHZ) for the Raman spectroscopy measurements. This work was financially supported by the European Union through Horizon 2020 research and innovation programme (Grant Agreement 819740, Project SCALEHALO).

\section{REFERENCES}

(1) Lin, H. R.; Zhou, C. K.; Tian, Y.; Siegrist, T.; Ma, B. W. LowDimensional Organometal Halide Perovskites. ACS Energy Lett. 2018, $3,54-62$.

(2) Zhou, G.; Su, B.; Huang, J.; Zhang, Q.; Xia, Z. Broad-Band Emission in Metal Halide Perovskites: Mechanism, Materials, and Applications. Mater. Sci. Eng., R 2020, 141, 100548.

(3) Smith, M. D.; Connor, B. A.; Karunadasa, H. I. Tuning the Luminescence of Layered Halide Perovskites. Chem. Rev. 2019, 119, 3104-3139.

(4) Li, S. R.; Luo, J. J.; Liu, J.; Tang, J. Self-Trapped Excitons in AllInorganic Halide Perovskites: Fundamentals, Status, and Potential Applications. J. Phys. Chem. Lett. 2019, 10, 1999-2007.

(5) Zhou, C. K.; Lin, H. R.; He, Q. Q.; Xu, L. J.; Worku, M.; Chaaban, M.; Lee, S.; Shi, X. Q.; Du, M. H.; Ma, B. W. Low Dimensional Metal Halide Perovskites and Hybrids. Mater. Sci. Eng., $R$ 2019, 137, 38-65.

(6) Dohner, E. R.; Jaffe, A.; Bradshaw, L. R.; Karunadasa, H. I. Intrinsic White-Light Emission from Layered Hybrid Perovskites. J. Am. Chem. Soc. 2014, 136, 13154-13157.

(7) Yangui, A.; Roccanova, R.; Wu, Y. T.; Du, M. H.; Saparov, B. Highly Efficient Broad-Band Luminescence Involving Organic and Inorganic Molecules in a Zero-Dimensional Hybrid Lead Chloride. J. Phys. Chem. C 2019, 123, 22470-22477.

(8) Morad, V.; Shynkarenko, Y.; Yakunin, S.; Brumberg, A.; Schaller, R. D.; Kovalenko, M. V. Disphenoidal Zero-Dimensional Lead, Tin, and Germanium Halides: Highly Emissive Singlet and Triplet SelfTrapped Excitons and X-ray Scintillation. J. Am. Chem. Soc. 2019, 141, 9764-9768.

(9) Zhou, C. K.; Tian, Y.; Wang, M. C.; Rose, A.; Besara, T.; Doyle, N. K.; Yuan, Z.; Wang, J. C.; Clark, R.; Hu, Y. Y.; Siegrist, T.; Lin, S. C.; Ma, B. W. Low-Dimensional Organic Tin Bromide Perovskites and Their Photoinduced Structural Transformation. Angew. Chem., Int. Ed. 2017, 56, 9018-9022.

(10) Benin, B. M.; Dirin, D. N.; Morad, V.; Worle, M.; Yakunin, S.; Raino, G.; Nazarenko, O.; Fischer, M.; Infante, I.; Kovalenko, M. V. Highly Emissive Self-Trapped Excitons in Fully Inorganic ZeroDimensional Tin Halides. Angew. Chem., Int. Ed. 2018, 57, 1132911333.

(11) Zhou, C. K.; Lin, H. R.; Shi, H. L.; Tian, Y.; Pak, C.; Shatruk, M.; Zhou, Y.; Djurovich, P.; Du, M. H.; Ma, B. W. A ZeroDimensional Organic Seesaw-Shaped Tin Bromide with Highly Efficient Strongly Stokes-Shifted Deep-Red Emission. Angew. Chem., Int. Ed. 2018, 57, 1021-1024.

(12) Fu, P. F.; Huang, M. L.; Shang, Y. Q.; Yu, N.; Zhou, H. L.; Zhang, Y. B.; Chen, S. Y.; Gong, J. K.; Ning, Z. J. Organic-Inorganic Layered and Hollow Tin Bromide Perovskite with Tunable Broadband Emission. ACS Appl. Mater. Interfaces 2018, 10, 3436334369.

(13) Mao, L. L.; Guo, P. J.; Kepenekian, M.; Hadar, I.; Katan, C.; Even, J.; Schaller, R. D.; Stoumpos, C. C.; Kanatzidis, M. G. Structural Diversity in White-Light-Emitting Hybrid Lead Bromide Perovskites. J. Am. Chem. Soc. 2018, 140, 13078-13088. 
(14) Yuan, Z.; Zhou, C. K.; Tian, Y.; Shu, Y.; Messier, J.; Wang, J. C.; van de Burgt, L. J.; Kountouriotis, K.; Xin, Y.; Holt, E.; Schanze, K.; Clark, R.; Siegrist, T.; Ma, B. W. One-Dimensional Organic Lead Halide Perovskites with Efficient Bluish White-Light Emission. Nat. Commun. 2017, 8, 14051.

(15) Zhou, C. K.; Lin, H. R.; Neu, J.; Zhou, Y.; Chaaban, M.; Lee, S.; Worku, M.; Chen, B. H.; Clark, R.; Cheng, W. H.; Guan, J. J.; Djurovich, P.; Zhang, D. Z.; Lu, X. J.; Bullock, J.; Pak, C.; Shatruk, M.; Du, M. H.; Siegrist, T.; Ma, B. W. Green Emitting Single-Crystalline Bulk Assembly of Metal Halide Clusters with Near-Unity Photoluminescence Quantum Efficiency. ACS Energy Lett. 2019, 4, 15791583.

(16) Zhou, C. K.; Worku, M.; Neu, J.; Lin, H. R.; Tian, Y.; Lee, S. J.; Zhou, Y.; Han, D.; Chen, S. Y.; Hao, A.; Djurovich, P. I.; Siegrist, T.; $\mathrm{Du}$, M. H.; Ma, B. W. Facile Preparation of Light Emitting Organic Metal Halide Crystals with Near-Unity Quantum Efficiency. Chem. Mater. 2018, 30, 2374-2378.

(17) Jing, Y. Y.; Liu, Y.; Zhao, J.; Xia, Z. G. $\mathrm{Sb}^{3+}$ Doping-Induced Triplet Self-Trapped Excitons Emission in Lead-Free $\mathrm{Cs}_{2} \mathrm{SnCl}_{6}$ Nanocrystals. J. Phys. Chem. Lett. 2019, 10, 7439-7444.

(18) Shen, N. N.; Cai, M. L.; Song, Y.; Wang, Z. P.; Huang, F. Q.; $\mathrm{Li}$ J. R.; Huang, X. Y. Supramolecular Organization of $\left[\mathrm{TeCl}_{6}\right]^{2-}$ with Ionic Liquid Cations: Studies on the Electrical Conductivity and Luminescent Properties. Inorg. Chem. 2018, 57, 5282-5291.

(19) Creason, T. D.; Yangui, A.; Roccanova, R.; Strom, A.; Du, M. H.; Saparov, B. $\mathrm{Rb}_{2} \mathrm{CuX}_{3}(\mathrm{X}=\mathrm{Cl}, \mathrm{Br})$ : $1 \mathrm{D}$ All-Inorganic Copper Halides with Ultrabright Blue Emission and Up-Conversion Photoluminescence. Adv. Opt. Mater. 2020, 8, 1901338.

(20) Roccanova, R.; Yangui, A.; Nhalil, H.; Shi, H.; Du, M.-H.; Saparov, B. Near-Unity Photoluminescence Quantum Yield in BlueEmitting $\mathrm{Cs}_{3} \mathrm{Cu}_{2} \mathrm{Br}_{5-\mathrm{x}} \mathrm{I}_{\mathrm{x}}(0 \leq \mathrm{x} \leq 5)$. ACS Appl. Electron. Mater. 2019, $1,269-274$.

(21) Roccanova, R.; Yangui, A.; Seo, G.; Creason, T. D.; Wu, Y. T.; Kim, D. Y.; Du, M. H.; Saparov, B. Bright Luminescence from Nontoxic $\mathrm{CsCu}_{2} \mathrm{X}_{3}(\mathrm{X}=\mathrm{Cl}, \mathrm{Br}, \mathrm{I})$. Acs Mater. Lett. 2019, 1, 459-465.

(22) Tan, Z. F.; Li, J. H.; Zhang, C.; Li, Z.; Hu, Q. S.; Xiao, Z. W.; Kamiya, T.; Hosono, H.; Niu, G. D.; Lifshitz, E.; Cheng, Y. B.; Tang, J. Highly Efficient Blue-Emitting Bi-Doped $\mathrm{Cs}_{2} \mathrm{SnCl}_{6}$ Perovskite Variant: Photoluminescence Induced by Impurity Doping. Adv. Funct. Mater. 2018, 28 (29), 1801131.

(23) Kshirsagar, A. S.; Nag, A. Synthesis and Optical Properties of Colloidal $\mathrm{Cs}_{2} \mathrm{AgSb}_{1-\mathrm{x}} \mathrm{BixCl}_{6}$ Double Perovskite Nanocrystals. J. Chem. Phys. 2019, 151 (16), 161101.

(24) Worku, M.; Tian, Y.; Zhou, C. K.; Lee, S.; Meisner, Q.; Zhou, Y.; Ma, B. W. Sunlike White-Light-Emitting Diodes Based on ZeroDimensional Organic Metal Halide Hybrids. ACS Appl. Mater. Interfaces 2018, 10, 30051-30057.

(25) Jun, T.; Sim, K.; Iimura, S.; Sasase, M.; Kamioka, H.; Kim, J.; Hosono, $\mathrm{H}$. Lead-Free Highly Efficient Blue-Emitting $\mathrm{Cs}_{3} \mathrm{Cu}_{2} \mathrm{I}_{5}$ with 0D Electronic Structure. Adv. Mater. 2018, 30, 1804547.

(26) Yakunin, S.; Benin, B. M.; Shynkarenko, Y.; Nazarenko, O.; Bodnarchuk, M. I.; Dirin, D. N.; Hofer, C.; Cattaneo, S.; Kovalenko, M. V. High-Resolution Remote Thermometry and Thermography Using Luminescent Low-Dimensional Tin-Halide Perovskites. Nat. Mater. 2019, 18, 846-852.

(27) Cao, J.; Guo, Z.; Zhu, S.; Fu, Y.; Zhang, H.; Wang, Q.; Gu, Z. Preparation of Lead-free Two-Dimensional-Layered $\left(\mathrm{C}_{8} \mathrm{H}_{17} \mathrm{NH}_{3}\right)_{2} \mathrm{SnBr}_{4}$ Perovskite Scintillators and Their Application in X-ray Imaging. ACS Appl. Mater. Interfaces 2020, 12, 19797-19804.

(28) Zhou, C. K.; Lin, H. R.; Tian, Y.; Yuan, Z.; Clark, R.; Chen, B. H.; van de Burgt, L. J.; Wang, J. C.; Zhou, Y.; Hanson, K.; Meisner, Q. J.; Neu, J.; Besara, T.; Siegrist, T.; Lambers, E.; Djurovich, P.; Ma, B. W. Luminescent Zero-Dimensional Organic Metal Halide Hybrids with Near-Unity Quantum Efficiency. Chem. Sci. 2018, 9, 586-593.

(29) Li, Z. Y.; Li, Y.; Liang, P.; Zhou, T. L.; Wang, L.; Xie, R. J. Dual-Band Luminescent Lead-Free Antimony Chloride Halides with Near-Unity Photoluminescence Quantum Efficiency. Chem. Mater. 2019, 31, 9363-9371.
(30) Zhou, C.; Lee, S.; Lin, H.; Neu, J.; Chaaban, M.; Xu, L.-J.; Arcidiacono, A.; He, Q.; Worku, M.; Ledbetter, L.; Lin, X.; Schlueter, J. A.; Siegrist, T.; Ma, B. Bulk Assembly of Multicomponent ZeroDimensional Metal Halides with Dual Emission. ACS Mater. Lett. 2020, 2, 376-380.

(31) Sedakova, T. V.; Mirochnik, A. G. Luminescence of Antimony(III) Halogenides Complexes with 2-and 4-Benzylpyridine. Russ. J. Phys. Chem. A 2017, 91, 791-795.

(32) Zhou, J.; Li, M.; Molokeev, M. S.; Sun, J.; Xu, D.; Xia, Z. Tunable Photoluminescence in $\mathrm{Sb}^{3+}$-Doped Zero-Dimensional Hybrid Metal Halides with Intrinsic and Extrinsic Self-Trapped Excitons. J. Mater. Chem. C 2020, 8, 5058.

(33) Saparov, B.; Hong, F.; Sun, J. P.; Duan, H. S.; Meng, W. W.; Cameron, S.; Hill, I. G.; Yan, Y. F.; Mitzi, D. B. Thin-Film Preparation and Characterization of $\mathrm{Cs}_{3} \mathrm{Sb}_{2} \mathrm{I}_{9}$ : A Lead-Free Layered Perovskite Semiconductor. Chem. Mater. 2015, 27, 5622-5632.

(34) Hebig, J. C.; Kuhn, I.; Flohre, J.; Kirchartz, T. Optoelectronic Properties of $\left(\mathrm{CH}_{3} \mathrm{NH}_{3}\right)_{2} \mathrm{Sb}_{2} \mathrm{I}_{9}$ Thin Films for Photovoltaic Applications. ACS Energy Lett. 2016, 1, 309-314.

(35) Stercho, I. P.; Barchii, I. E.; Malakhovskaya, T. A.; Pogodin, A. I.; Sidei, V. I.; Solomon, A. M.; Peresh, E. Y. Physicochemical Interaction in the $\mathrm{Cs}_{3} \mathrm{Sb}_{2} \mathrm{Br}_{9}-\mathrm{Cs}_{2} \mathrm{TeBr}_{6}$ system: The Phase Diagram and the Nature of the Interaction of Components. Russ. J. Inorg. Chem. 2015, 60, 225-229.

(36) Timmermans, C. W. M.; Cholakh, S. O.; Blasse, G. The Luminescence of $\mathrm{Cs}_{3} \mathrm{Bi}_{2} \mathrm{Cl}_{9}$ and $\mathrm{Cs}_{3} \mathrm{Sb}_{2} \mathrm{Cl}_{9}$. J. Solid State Chem. 1983, 46, 222-233.

(37) Wang, Z. P.; Wang, J. Y.; Li, J. R.; Feng, M. L.; Zou, G. D.; Huang, X. Y. $[\mathrm{Bmim}]_{2} \mathrm{SbCl}_{5}$ : a Main Group Metal-Containing Ionic Liquid Exhibiting Tunable Photoluminescence and White-Light Emission. Chem. Commun. 2015, 51, 3094-3097.

(38) Petrochenkova, N. V.; Storozhuk, T. V.; Mirochnik, A. G.; Karasev, V. E. Antimony(III) Complexes with Quaternary Ammonium Bases: Synthesis, Spectral, and Luminescent properties. Russ. J. Coord. Chem. 2002, 28, 468-472.

(39) Wang, Z. P.; Zhang, Z. Z.; Tao, L. Q.; Shen, N. N.; Hu, B.; Gong, L. K.; Li, J. R.; Chen, X. P.; Huang, X. Y. Hybrid Chloroantimonates(III): Thermally Induced Triple-Mode Reversible Luminescent Switching and Laser- Printable Rewritable Luminescent Paper. Angew. Chem., Int. Ed. 2019, 58, 9974-9978.

(40) Chen, D.; Dai, F.; Hao, S.; Zhou, G.; Liu, Q.; Wolverton, C. M.; Zhao, J.; Xia, Z. Crystal Structure and Luminescence Properties of Lead-Free Metal Halides: $\left(\mathrm{C}_{6} \mathrm{H}_{5} \mathrm{CH}_{2} \mathrm{NH}_{3}\right)_{3} \mathrm{MBr}_{6}(\mathrm{M}=\mathrm{Bi}$ and $\mathrm{Sb}) . J$. Mater. Chem. C 2020, 8, 7322-7329.

(41) Sedakova, T. V.; Mirochnik, A. G.; Karasev, V. E. Structure and Luminescence Properties of Antimony(III) Complex Compounds. Opt. Spectrosc. 2008, 105, 517-523.

(42) Zhao, J.; Zhang, T. J.; Dong, X. Y.; Sun, M. E.; Zhang, C.; Li, X. L.; Zhao, Y. S.; Zang, S. Q. Circularly Polarized Luminescence from Achiral Single Crystals of Hybrid Manganese Halides. J. Am. Chem. Soc. 2019, 141, 15755-15760.

(43) Wojciechowska, M.; Szklarz, P.; Bialonska, A.; Baran, J.; Janicki, R.; Medycki, W.; Durlak, P.; Piecha-Bisiorek, A.; Jakubas, R. Enormous Lattice Distortion Through an Isomorphous Phase Transition in an Organic-Inorganic Hybrid Based on Haloantimonate(III). CrystEngComm 2016, 18, 6184-6194.

(44) Seitz, F. Interpretation of the Properties of Zinc Sulphide Phosphors. J. Chem. Phys. 1938, 6, 454-461.

(45) Jacobs, P. W. M. Alkali-Halide Crystals Containing Impurity Ions with the $\mathrm{ns}^{2}$ Ground-State Electronic Configuration. J. Phys. Chem. Solids 1991, 52, 35-67.

(46) Vogler, A.; Nikol, H. The Structures of $\mathrm{s}^{2}$ Metal Complexes in the Ground and sp Excited States. Comments Inorg. Chem. 1993, 14, $245-261$.

(47) Oomen, E. W. J. L.; Smit, W. M. A.; Blasse, G. Jahn-Teller Effect in the $\mathrm{Sb}^{3+}$ Emission in Zircon-Structured Phosphates. Chem. Phys. Lett. 1984, 112, 547-550.

(48) Oomen, E. W. J. L.; Smit, W. M. A.; Blasse, G. The Luminescence of $\mathrm{Cs}_{2} \mathrm{NaSbCl}_{6}$ and $\mathrm{Cs}_{2} \mathrm{NaSbBr}_{6}$ : a Transition from a 
Localized to a Delocalized Excited State. Chem. Phys. Lett. 1987, 138, 23-28.

(49) Han, D.; Shi, H. L.; Ming, W. M.; Zhou, C. K.; Ma, B. W.; Saparov, B.; Ma, Y. Z.; Chen, S. Y.; Du, M. H. Unraveling Luminescence Mechanisms in Zero-Dimensional Halide Perovskites. J. Mater. Chem. C 2018, 6, 6398-6405.

(50) McCall, K. M.; Stoumpos, C. C.; Kostina, S. S.; Kanatzidis, M. G.; Wessels, B. W. Strong Electron-Phonon Coupling and SelfTrapped Excitons in the Defect Halide Perovskites $\mathrm{A}_{3} \mathrm{M}_{2} \mathrm{I}_{9}(\mathrm{~A}=\mathrm{Cs}$, $\mathrm{Rb} ; \mathrm{M}=\mathrm{Bi}, \mathrm{Sb})$. Chem. Mater. 2017, 29, 4129-4145.

(51) Savchuk, O. A.; Haro-Gonzalez, P.; Carvajal, J. J.; Jaque, D.; Massons, J.; Aguilo, M.; Diaz, F. Er: $\mathrm{Yb}: \mathrm{NaY}_{2} \mathrm{~F}_{5} \mathrm{O}$ Up-Converting Nanoparticles for Sub-Tissue Fluorescence Lifetime Thermal Sensing. Nanoscale 2014, 6, 9727-9733. 